\title{
The efficacy and safety of apatinib treatment for patients with advanced or recurrent biliary tract cancer: a retrospective study
}

Caiyun Nie ${ }^{1,2}$, Huifang LV $v^{1,2}$, Yishu Xing ${ }^{1,2}$, Beibei Chen ${ }^{1,2}$, Weifeng $X u^{1,2}$, Jianzheng Wang ${ }^{1,2}$ and Xiaobing Chen ${ }^{1,2^{*}}$ (1)

\begin{abstract}
Introduction: The present study aims to evaluate the efficacy and safety of apatinib monotherapy or combination therapy for patients with advanced or recurrent biliary tract cancer (BTC).

Methods: Twenty-eight patients with advanced or recurrent BTC who progressed after prior systemic therapies and treated with apatinib from January 2017 to June 2019 were enrolled in this retrospective and observational study. The primary end point was progression free survival (PFS). Secondary end points included overall survival (OS), objective response rate (ORR), disease control rate (DCR), and toxicity.

Results: A total of 28 patients with advanced or recurrent BTC who progressed after prior systemic therapies received apatinib monotherapy or combination therapy (with capecitabine, S-1, oxaliplatin, irinotecan or PD-1 inhibitor), including 9 cases of gallbladder cancer and 19 cases of cholangiocarcinoma. Six patients achieved PR, 15 patients had SD and 7 patients had PD. Median progression-free survival (PFS) and overall survival (OS) was 4.3 months $(95 \% \mathrm{Cl}=1.8-6.8)$ and 6.2 months $(95 \% \mathrm{Cl}=4.6-7.8)$ respectively. The ORR and DCR were $21.4 \%(6 / 28)$ and $75.0 \%(21 /$ 28), respectively. Most of the adverse events were grade 1-2 in severity, apatinib treatment was well tolerated.
\end{abstract}

Conclusions: Apatinib monotherapy or combination therapy can improve PFS in patients with advanced or recurrent BTC who progressed after prior systemic therapies, and adverse reactions can be well tolerated. Our study support apatinib therapy as a feasible therapeutic strategy in advanced or recurrent BTC.

Keywords: Biliary tract cancer, Apatinib, Targeted therapy, Efficacy

\section{Introduction}

Biliary tract cancer (BTC) includes gallbladder cancers (GBCs) and cholangiocarcinomas (CCAs), further divided into intrahepatic cholangiocarcinomas (iCCAs) and extrahepatic cholangiocarcinomas (eCCAs). The

\footnotetext{
* Correspondence: cxbmed@126.com

'Department of Oncology, The Affiliated Cancer Hospital of Zhengzhou University, No. 127 Dongming Road, Jinshui District, Zhengzhou City 450008, Henan Province, China

${ }^{2}$ Henan Cancer Hospital, Zhengzhou 450008, China
}

incidence of iCCAs in the western world is rising, and the incidence of GBCs is on the decline $[1,2]$. The onset of BTC is hidden, lacking specific clinical manifestations in the early stage, and most patients are already in the advanced stage at the time of diagnosis, losing the chance of radical surgical resection and having a poor prognosis. Advanced or recurrent BTC is dominated by systemic medications. Prospective randomized controlled studies have shown that systemic chemotherapy can prolong the survival of patients with BTC. However,

(c) The Author(s). 2021 Open Access This article is licensed under a Creative Commons Attribution 4.0 International License, which permits use, sharing, adaptation, distribution and reproduction in any medium or format, as long as you give appropriate credit to the original author(s) and the source, provide a link to the Creative Commons licence, and indicate if changes were made. The images or other third party material in this article are included in the article's Creative Commons licence, unless indicated otherwise in a credit line to the material. If material is not included in the article's Creative Commons licence and your intended use is not permitted by statutory regulation or exceeds the permitted use, you will need to obtain permission directly from the copyright holder. To view a copy of this licence, visit http://creativecommons.org/licenses/by/4.0/. The Creative Commons Public Domain Dedication waiver (http://creativecommons.org/publicdomain/zero/1.0/) applies to the data made available in this article, unless otherwise stated in a credit line to the data. 
the effect of systemic chemotherapy is limited. There is no effective second-line standard treatment after firstline chemotherapy. New treatment strategies are urgently needed $[3,4]$.

Apatinib is an oral, highly selective VEGFR2 antagonist, and was approved by the China Food and Drug Administration for use as a single agent in patients with advanced gastric or gastroesophageal junction adenocarcinoma after second line chemotherapy failure [5]. In addition, apatinib has also showed good clinical efficacy in a variety of solid tumors, including lung [6], liver [7], ovarian [8], breast [9], colorectal [10] and bone soft tissue sarcoma [11]. Preclinical studies demonstrated that apatinib affect VEGF-mediated cell proliferation and migration in cholangiocarcinoma cell [12], however, clinical use of apatinib in BTC was rarely investigated. This retrospective and observational study was performed to evaluate the efficacy and safety of apatinib monotherapy or combination therapy for patients with advanced or recurrent BTC who progressed after prior systemic therapies.

\section{Methods}

\section{Patients}

From January 2017 to June 2019, a total of 28 patients with advanced or recurrent BTC received apatinib monotherapy or combination therapy at the Affiliated Cancer Hospital of Zhengzhou University were enrolled in the present study. Inclusion criteria were pathologically confirmed as BTC, including gallbladder cancers and cholangiocarcinomas; advanced or recurrent BTC who progressed after prior systemic therapies according to imaging examination; have at least one measurable lesion. This study was carried out in accordance with the ethical guidelines of the 1975 Declaration of Helsinki and was approved by the ethics committee of the Affiliated Cancer Hospital of Zhengzhou University. Written informed consent was obtained from every patient for the use of the medical records for research purposes.

\section{Treatment}

Apatinib was provided as tablets and administered orally daily until disease progression, unacceptable toxicity or death. In this study, the patients received two dosing regimens, including apatinib monotherapy or combination therapy. In the monotherapy regimen, apatinib was given at a dose of $500 \mathrm{mg}$ once a day, and dose reduction to no less than $250 \mathrm{mg}$ once a day was allowed. In the combination therapy regimen, apatinib was given at a dose of $250 \mathrm{mg}$ once a day, and concurrent chemotherapy or immunotherapy was given simultaneously, including capecitabine, S-1, oxaliplatin, irinotecan or PD-1 inhibitor. There were no dose modifications but only delays or permanent discontinuation in this group.

\section{Efficacy and safety assessments}

Imaging examination were performed after every 2 cycles to evaluate the efficacy of treatment. Clinical efficacy of patients was classified as having a complete response $(\mathrm{CR})$, partial response (PR), stable disease (SD), or progressive disease (PD) according to RECIST version 1.1 response evaluation criteria in solid tumors. Objective response rate (ORR) was defined as the proportion of patients who achieved a confirmed CR or PR. Disease control rate (DCR) was defined as the proportion of patients who achieved CR, PR and SD. Adverse events (AEs) were assessed according to the Common Terminology Criteria for Adverse Events, version 4.0. During treatment, performance status, abdominal and cardiac ultrasound, electrocardiogram, complete blood count, liver and kidney function were monitored regularly in every cycle.

\section{Statistical analysis}

Difference between groups were determined by Pearson's chi squared test or Fisher's exact test. Survival curves were estimated using the Kaplan-Meier method and the log-rank test was used to test for differences between the groups. PFS was defined as the period from the time of treatment with apatinib to disease progression or patient death due to any cause. OS was defined as the period from the time of treatment with apatinib to patient death from any cause or the last day of the follow-up. The follow-up deadline is December 31, 2019. All the statistical descriptive analyses were performed with SPSS 17.0 (SPSS, Chicago, IL) software.

\section{Results}

Patient and treatment characteristics

A total of 28 patients with advanced or recurrent BTC were included in this retrospective study. Patient and treatment characteristics are summarized in Table 1 and Table 2. The median age was 54 years (range 36-79), 12 female patients and 16 male patients. Nine patients were diagnosed as GBC and the other patients were CCA. Based on the anatomical locations, the 19 cases of CCA classified as 6 cases of intrahepatic, 8 cases of perihilar, and 5 cases of distal tumors. All the patients were advanced or recurrent BTC, common metastatic sites included intra-abdominal lymph node (57.1\%), liver (50.0\%), peritoneum (28.6\%) and lung (28.6\%) according to imaging examination. Other metastatic sites were mediastinum, supraclavicular lymph nodes, bones, and etc. All the patients in the study had undergone prior systemic therapies, so apatinib was given as second line treatment in 11 patients (39.3\%) and third- or fourthline treatment in 17 patients $(60.7 \%)$. Twelve patients received apatinib as monotherapy and 16 patients received apatinib combination therapy. 
Table 1 Patient and treatment characteristics

\begin{tabular}{|c|c|c|c|c|}
\hline Characteristic & $\begin{array}{l}\text { Total }(n=28) \\
n(\%)\end{array}$ & $\begin{array}{l}\text { Monotherapy }(n=12) \\
n(\%)\end{array}$ & $\begin{array}{l}\text { Combination therapy }(n=16) \\
\text { n }(\%)\end{array}$ & $P$ \\
\hline Age (years, median) & $54(36-79)$ & $52(36-79)$ & $57(43-64)$ & \\
\hline \multicolumn{5}{|l|}{ Sex } \\
\hline Female & $12(42.9)$ & $5(41.7)$ & $7(43.8)$ & \multirow[t]{2}{*}{0.912} \\
\hline Male & $16(57.1)$ & $7(58.3)$ & $9(56.2)$ & \\
\hline \multicolumn{5}{|l|}{ ECOG } \\
\hline $0-1$ & $22(78.6)$ & $10(83.3)$ & $12(75.0)$ & \multirow[t]{2}{*}{0.595} \\
\hline 2 & $6(21.4)$ & $2(16.7)$ & $4(25.0)$ & \\
\hline \multicolumn{5}{|l|}{ Primary tumor site } \\
\hline GBC & $9(32.1)$ & $3(25.0)$ & $6(37.5)$ & \multirow[t]{2}{*}{0.483} \\
\hline CCA & $19(67.9)$ & $9(75.0)$ & $10(62.5)$ & \\
\hline \multicolumn{5}{|l|}{ Metastatic site } \\
\hline Intra-abdominal lymph node & $16(57.1)$ & $6(50.0)$ & $10(62.5)$ & \multirow{5}{*}{0.086} \\
\hline Liver & $14(50.0)$ & $2(16.7)$ & $12(75.0)$ & \\
\hline Peritoneum & $8(28.6)$ & $3(25.0)$ & $5(31.3)$ & \\
\hline Lung & $8(28.6)$ & $6(50.0)$ & $2(12.5)$ & \\
\hline Others & $16(57.1)$ & $7(58.3)$ & $9(56.3)$ & \\
\hline \multicolumn{5}{|l|}{ Number of metastatic sites } \\
\hline $1-2$ & $13(46.4)$ & $5(41.7)$ & $8(50.0)$ & \multirow[t]{2}{*}{0.662} \\
\hline $\begin{array}{l}\geq 3 \\
\text { Treatment line }\end{array}$ & $15(53.6)$ & $7(58.3)$ & $8(50.0)$ & \\
\hline 2 & $11(39.3)$ & $5(41.7)$ & $6(37.5)$ & \multirow[t]{2}{*}{0.823} \\
\hline $3-4$ & $17(60.7)$ & $7(58.3)$ & $10(62.5)$ & \\
\hline
\end{tabular}

ECOG Eastern Cooperative Oncology Group performance status, GBC gallbladder cancer, CCA Cholangiocarcinoma

\section{Efficacy}

Treatment efficacy was evaluated in the 28 patients with advanced or recurrent BTC who progressed after prior systemic therapies, CR was not observed. In the general population, 6 patients achieved PR, 15 patients had SD and 7 patients had PD. The ORR and DCR were $21.4 \%$ $(6 / 28)$ and $75.0 \%(21 / 28)$, respectively. In apatinib monotherapy population, 2 patients achieved PR, 8 patients had SD and 2 patients had PD, the ORR and DCR were $16.7 \%(2 / 12)$ and $83.3 \%(10 / 12)$, respectively. In combination therapy population, 4 patients achieved PR, 7 patients had SD and 5 patients had PD, the ORR and DCR were $25.0 \%(4 / 16)$ and $68.8 \%(11 / 16)$, respectively

Table 2 Characteristics of Combination therapy

\begin{tabular}{ll}
\hline Characteristic & Total $\mathbf{n}(\%)$ \\
\hline Capecitabine & $1(6.3)$ \\
S-1 & $8(50.0)$ \\
Oxaliplatin & $1(6.3)$ \\
Irinotecan & $2(12.2)$ \\
PD-1 inhibitor & $4(25.0)$ \\
\hline
\end{tabular}

PD-1 Programmed cell death-1
(Table 3). With a median follow-up of 14.8 months (range, $7.1 \mathrm{~m}$ to $35.7 \mathrm{~m}$ ), median PFS and OS in the 28 patients with advanced or recurrent BTC patients were 4.3 months $\quad(95 \%$ confidence interval $[\mathrm{CI}]=1.8-$ 6.8)(Fig. 1a) and 6.2 (95\% CI = 4.6-7.8) months (Fig. 1b) respectively. The median PFS in patients who received mono- and combo-regimens was $4.2(95 \% \mathrm{CI}=2.8-5.6)$ and $4.9(95 \% \mathrm{CI}=0.4-9.4)$ months respectively, and OS was $7.0(95 \% \mathrm{CI}=4.7-9.2)$ and 6.1 (95\% CI $=3.8-8.4)$ months respectively.

\section{Safety}

In terms of safety, apatinib treatment was well tolerated, disease progression was the leading cause of discontinuation of treatment, and only 1 patient discontinued treatment due to intolerable toxicity. Most of the adverse events were grade 1-2 in severity, which could be relieved by symptomatic treatment (Table 4). A small number of patients experienced grade 3-4 adverse reactions, including secondary hypertension (2 cases), hand-foot syndrome (1 case) and neutropenia (1 case). No unexpected side effects or treatment-related death were observed. Dose reduction occurred in two patients 
Table 3 Efficacy of apatinib in patients with BTC

\begin{tabular}{|c|c|c|c|c|}
\hline Parameter & $\begin{array}{l}\text { Total }(n=28) \\
\text { n (\%) }\end{array}$ & $\begin{array}{l}\text { Monotherapy }(n=12) \\
\mathrm{n}(\%)\end{array}$ & $\begin{array}{l}\text { Combination therapy }(n=16) \\
n(\%)\end{array}$ & $P$ \\
\hline Best response & & & & 0.478 \\
\hline$C R$ & $0(0)$ & $0(0)$ & $0(0)$ & \\
\hline PR & $6(21.4)$ & $2(16.7)$ & $4(25.0)$ & \\
\hline SD & $15(53.6)$ & $8(66.6)$ & $7(43.8)$ & \\
\hline PD & $7(25.0)$ & $2(16.7)$ & $5(31.2)$ & \\
\hline ORR & $6(21.4)$ & $2(16.7)$ & $4(25.0)$ & 0.595 \\
\hline DCR & $21(75.0)$ & $10(83.3)$ & $11(68.8)$ & 0.378 \\
\hline Median PFS (months) & 4.3 & 4.2 & 4.9 & 0.867 \\
\hline Median OS (months) & 6.2 & 7.0 & 6.1 & 0.871 \\
\hline
\end{tabular}

adjusting the dosage from 500 to $250 \mathrm{mg}$ due to adverse events in apatinib monotherapy population. In apatinib monotherapy population, the most common adverse events were secondary hypertension $(n=5 ; 41.7 \%)$, hand and foot syndrome $(n=3 ; 25.0 \%)$, fatigue $(n=3 ; 25.0 \%)$ and $\operatorname{proteinuria}(n=2 ; 16.7 \%)$. In combination therapy population, the most common adverse events were neutropenia $(n=7 ; 43.8 \%)$, nausea $(n=4 ; 25.0 \%)$, secondary hypertension $(n=3 ; 18.8 \%)$, hand and foot syndrome $(\mathrm{n}=$ 3; 18.8\%).

\section{Discussion}

BTC is a rare but highly malignant tumor. $60-70 \%$ of new BTC cases are diagnosed as advanced stage [13, 14]. Patients of advanced BTC have a very poor prognosis with a median OS less than 12 months [14]. Prospective randomized control studies have shown that systemic chemotherapy can prolong the survival of patients with advanced BTC compared with optimal supportive care [15].
Based on the results of a phase III randomized controlled ABC-02 study, gemcitabine and cisplatin are recommended as the first-line standard treatment regimen for advanced, which can reduce the OS of patients with advanced BTC from 8.1 Month increased to 11. Seven months [16]. In the meantime, gemcitabine combined with S-1 was also recommended as first-line treatment options for advanced BTC $[17,18]$. However, there are no clear second-line treatment options for those with disease progression after first-line treatment. Summary of first-line treatment in BTC and in advanced BTC are displayed in Table S1 and Table S2. New treatment strategies are urgently needed.

Currently, cancer therapy has entered the era of molecular therapy, and targeted therapy based on genetic changes has become an effective strategy for cancer [19]. Numerous studies have demonstrated the landscape of molecular mutations in BTC, including EGFR pathway, HER2 (ERBB2), VEGF pathway, PI3K/mTOR signaling cascade, FGFR pathway, IDH1, MEK pathway and etc.

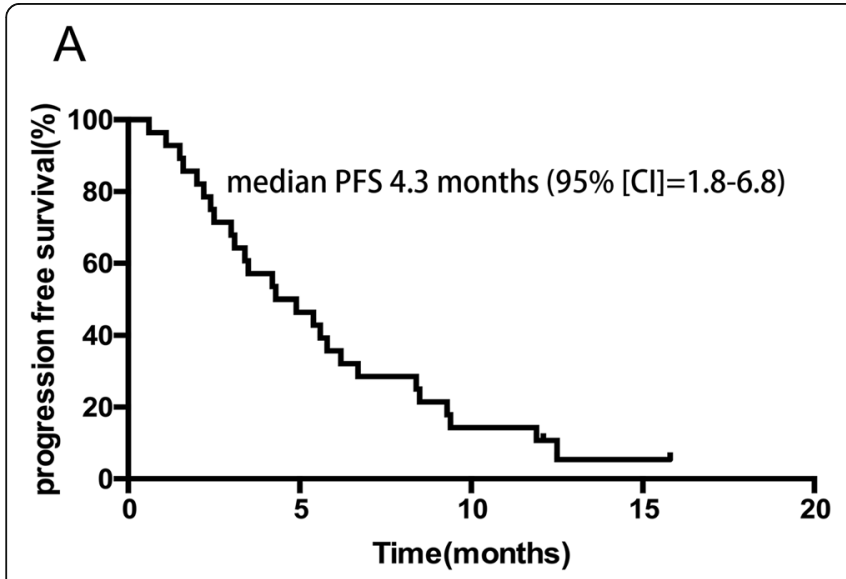

B

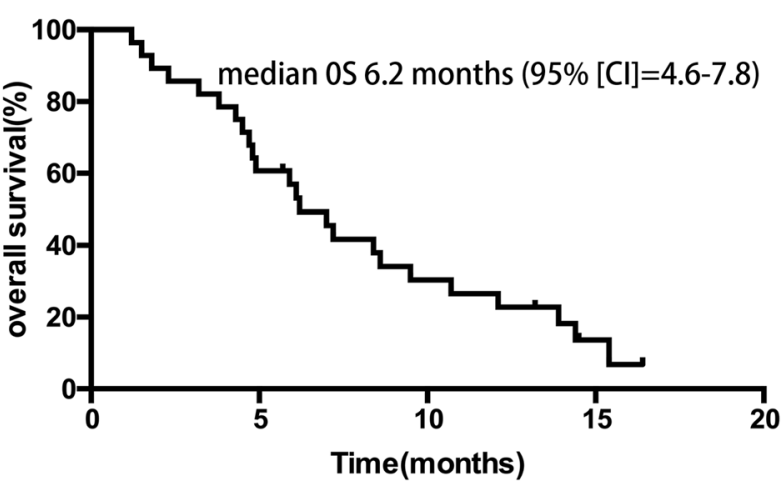

Fig. 1 Kaplan-Meier curve of progression-free survival (a) and overall survival (b) 
Table 4 Treatment-Related Toxicities

\begin{tabular}{|c|c|c|c|c|c|}
\hline Adverse Event & Grade1 n(\%) & Grade2 n(\%) & Grade3 n(\%) & Grade4 n(\%) & Total $n(\%)$ \\
\hline \multicolumn{6}{|l|}{ Monotherapy $\operatorname{group}(n=12)$} \\
\hline Secondary hypertension & $1(8.3)$ & $2(16.7)$ & $1(8.3)$ & $1(8.3)$ & $5(41.7)$ \\
\hline Hand-foot syndrome & $1(8.3)$ & $1(8.3)$ & $1(8.3)$ & 0 & $3(25.0)$ \\
\hline Proteinuria & $2(16.7)$ & 0 & 0 & 0 & $2(16.7)$ \\
\hline Fatigue & $1(8.3)$ & $2(16.7)$ & 0 & 0 & $3(25.0)$ \\
\hline Diarrhea & $1(8.3)$ & 0 & 0 & 0 & $1(8.3)$ \\
\hline \multicolumn{6}{|l|}{ Combination group $(n=16)$} \\
\hline Secondary hypertension & $2(12.5)$ & $1(6.3)$ & 0 & 0 & $3(18.8)$ \\
\hline Hand-foot syndrome & $1(6.3)$ & $2(12.5)$ & 0 & 0 & $3(18.8)$ \\
\hline Proteinuria & $2(12.5)$ & 0 & 0 & 0 & $2(12.5)$ \\
\hline Nausea & $2(12.5)$ & $2(12.5)$ & 0 & 0 & $4(25.0)$ \\
\hline Neutropenia & $5(31.3)$ & $1(6.3)$ & $1(6.3)$ & 0 & $7(43.8)$ \\
\hline
\end{tabular}

[20-23]. As a tyrosine kinase inhibitor that selectively inhibits the vascular endothelial growth factor receptor2 (VEGFR2), apatinib has showed good clinical efficacy in a variety of solid tumors. Previous study demonstrated that apatinib inhibits VEGF-mediated cell migration and invasion of CCA cell lines [12], and apatinib promotes apoptosis in intrahepatic cholangiocarcinoma [24], which highlight the potential clinical utility of apatinib in BTC. However, clinical use of apatinib in BTC is rarely reported. Only one case report investigated the clinical efficacy and safety of apatinib in advanced or recurrent BTC [25].

In our present study, treatment efficacy of apatinib was evaluated in the 28 patients with advanced or recurrent BTC who progressed after prior systemic therapies. Although CR was not observed, the ORR and DCR reached to 21.4 and $75.0 \%$ respectively, median PFS and OS were 4.3 month and 6.2 months. There are very few studies on standard second-line treatment regimens after first-line chemotherapy failure in BTC. In the phase III randomized controlled ABC-06 study, oxaliplatin combined with 5-FU (mFOLFOX) solution second-line chemotherapy increased OS from 5.3 months to 6.2 months, with a median PFS of 4.0 months. In another randomized phase II study of second-line XELIRI regimen versus irinotecan monotherapy in BTC, median PFS were 3.7 and 2.4 months respectively [26]. PFS and OS survival in our present study was superior. It is noteworthy that, approximately $60 \%$ patients received apatinib as third- or fourth-line treatment, but still got a good response and improved survival.

Apatinib targeted therapeutics showed efficacy both in apatinib monotherapy and combination therapy patients. In combination therapy population, 3 patients received apatinib plus PD-1 inhibitor, of which one patient achieved PR, and the other 2 patients had SD. Our study suggested that compared with traditional pure cytotoxic drugs, targeted therapy has unique advantages and application prospects. For patients with advanced BTC, targeted therapy or targeted therapy combined with chemotherapy and immunotherapy may be new treatment strategies, and more clinical researches should be conducted [27].

Advanced or recurrent BTC is incurable, and its treatment is palliative, with the goal of extending survival. Gentle, effective and concerned about the quality of life are the basic principles of treatment. Therefore, treatment-related toxicity is also a major evaluation indicator. Commonly reported apatinib-related AEs included secondary hypertension, hand and foot syndrome, fatigue and proteinuria, a similar safety profile was observed in the present study. Most of the adverse events were grade 1-2 in severity, and no unexpected side effects or treatment-related death were observed. Dose reduction occurred in only two patients adjusting the dosage from 500 to $250 \mathrm{mg}$ due to adverse events in apatinib monotherapy population. In combination therapy population, the above incidence of apatinib-related adverse reactions is lower, but the incidence of hematological toxicity is relatively higher due to utilization of chemotherapy. In general, apatinib treatment was well tolerated.

Our study has some limitations, because it is a retrospective study obtained from a single center, and the number of cases enrolled is not very large. However, the efficacy that median PFS in the 28 patients with advanced or recurrent BTC patients who had undergone prior systemic therapies reached to 4.3 months is still encouraging. Thus, large randomized controlled trials from multi-center are needed to confirm the clinical value of apatinib in advanced or recurrent BTC. 


\section{Conclusions}

In conclusion, our present study evaluated the efficacy and safety of apatinib in advanced or recurrent BTC, a median PFS of 4.3 months was obtained with well tolerated toxicity. These promising results support apatinib therapy as a feasible therapeutic strategy in advanced or recurrent BTC.

\section{Supplementary Information}

The online version contains supplementary material available at https:/doi. org/10.1186/s12885-021-07907-4

\section{Additional file 1.}

Additional file 2 .

\section{Abbreviations}

BTC: Biliary tract cancer; PFS: Progression free survival; OS: Overall survival ORR: Objective response rate; DCR: Disease control rate; GBCs: Gallbladder cancers; CCAs: Cholangiocarcinomas; iCCAs: Intrahepatic cholangiocarcinomas; eCCAs: Extrahepatic cholangiocarcinomas; CR: Complete response; PR: Partial response; SD: Stable disease; PD: Progressive disease; AEs: Adverse events

\section{Acknowledgments}

We thank all the authors and those who helped in the preparation of the study.

\section{Authors' contributions}

Conceptualization: CY N, XB C. Retrieve data: YS X, BB C, JZ W, WF X. Formal analysis: $C Y N, H F L, X B C$. Funding acquisition: $X B C$. Writing original draft: CY N, XB C. Writing - review \& editing: CY N, XB C. All authors read and approved the final manuscript and agree to be accountable for all aspects of the work.

\section{Funding}

Data collection and follow-up in this work was supported by the Nationa Natural Science Foundation of China (No. 81472714). The funding bodies played no role in the design of the study and collection, analysis, and interpretation of data and in writing the manuscript.

\section{Availability of data and materials}

The datasets used and analyzed during the current study are available from the corresponding author on reasonable request.

\section{Ethics approval and consent to participate}

This study was carried out in accordance with the ethical guidelines of the 1975 Declaration of Helsinki and was approved by the ethics committee of the Affiliated Cancer Hospital of Zhengzhou University (IRB No.2019041). Written informed consent was obtained from every patient for the use of the medical records for research purposes.

\section{Consent for publication}

Not applicable.

\section{Competing interests}

The authors have declared that no competing interests exist.

Received: 17 August 2020 Accepted: 12 February 2021

Published online: 23 February 2021

\section{References}

1. Bridgewater JA, Goodman KA, Kalyan A, Mulcahy MF. Biliary tract Cancer: epidemiology, radiotherapy, and molecular profiling. Am Soc Clin Oncol Educ Book. 2016;35:e194-203.

2. Shaib Y, El-Serag HB. The epidemiology of cholangiocarcinoma. Semin Liver Dis. $2004 ; 24(2): 115-25$.
3. Marks El, Yee NS. Molecular genetics and targeted therapeutics in biliary tract carcinoma. World J Gastroenterol. 2016:22(4):1335-47.

4. Sirica AE, Gores GJ, Groopman JD, Selaru FM, Strazzabosco M, Wei Wang X, Zhu AX. Intrahepatic Cholangiocarcinoma: continuing challenges and translational advances. Hepatology. 2019;69(4):1803-15.

5. Li J, Qin S, Xu J, Xiong J, Wu C, Bai Y, Liu W, Tong J, Liu Y, Xu R, et al. Randomized, double-blind, placebo-controlled phase III trial of Apatinib in patients with chemotherapy-refractory advanced or metastatic adenocarcinoma of the stomach or Gastroesophageal junction. J Clin Oncol. 2016;34(13):1448-54

6. Song ZZ, Zhao LF, Zuo J, Fan ZS, Wang L, Wang YD. Clinical outcomes and safety of Apatinib Mesylate in the treatment of advanced non-squamous non-small cell lung Cancer in patients who progressed after standard therapy and analysis of the KDR gene polymorphism. Onco Targets Ther. 2020;13:603-13.

7. Zhen L, Jiali C, Yong F, Han X, Hongming P, Weidong $H$. The efficacy and safety of Apatinib treatment for patients with Unresectable or relapsed liver Cancer: a retrospective study. J Cancer. 2018;9(16):2773-7.

8. Zhang J, Li A, Jiang Q, Zheng F, Zhu H. Efficacy and safety of Apatinib treatment in platinum-resistant recurrent epithelial ovarian Cancer: a real world study. Drug Des Devel Ther. 2019;13:3913-8.

9. Zhu A, Yuan P, Wang J, Fan Y, Luo Y, Cai R, Zhang P, Li Q, Ma F, Xu B. Apatinib combined with chemotherapy in patients with previously treated advanced breast cancer: An observational study. Oncol Lett. 2019;17(6): 4768-78.

10. Xin M, Xie Q, Ma L, An G, Xiao J, Li J, Liu X, Gao P, Liang J, Li Y. Synergistic anti-tumour effects of Clostridium butyricum in combination with apatinib in CT26 colorectal tumour-bearing mice. Anti-Cancer Drugs. 2019;30(10): 991-7.

11. Zhu B, Li J, Xie Q, Diao L, Gai L, Yang W. Efficacy and safety of apatinib monotherapy in advanced bone and soft tissue sarcoma: An observational study. Cancer Biol Ther. 2018;19(3):198-204.

12. Huang M, Huang B, Li G, Zeng S. Apatinib affect VEGF-mediated cell proliferation, migration, invasion via blocking VEGFR2/RAF/MEK/ERK and PI3K/AKT pathways in cholangiocarcinoma cell. BMC Gastroenterol. 2018; 18(1):169.

13. Ghidini M, Pizzo C, Botticelli A, Hahne JC, Passalacqua R, Tomasello G, Petrelli F. Biliary tract cancer: current challenges and future prospects. Cancer Manag Res. 2019;11:379-88.

14. Valle JW, Lamarca A, Goyal L, Barriuso J, Zhu AX. New horizons for precision medicine in biliary tract cancers. Cancer Discov. 2017;7(9):943-62

15. Ghosn M, Kourie HR, El Rassy E, Chebib R, El Karak F, Hanna C, Nasr D. Optimum chemotherapy for the management of advanced biliary tract cancer. World J Gastroenterol. 2015;21(14):4121-5.

16. Valle J, Wasan H, Palmer DH, Cunningham D, Anthoney A, Maraveyas A, Madhusudan S, Iveson T, Hughes S, Pereira SP, et al. Cisplatin plus gemcitabine versus gemcitabine for biliary tract cancer. N Engl J Med. 2010; 362(14):1273-81

17. Mizusawa J, Morizane C, Okusaka T, Katayama H, Ishii H, Fukuda H, Furuse J. Hepatobiliary, pancreatic oncology Group of the Japan Clinical Oncology G: randomized phase III study of gemcitabine plus S-1 versus gemcitabine plus cisplatin in advanced biliary tract cancer: Japan clinical oncology group study (JCOG1113, FUGA-BT). Jpn J Clin Oncol. 2016:46(4):385-8.

18. Morizane C, Okusaka T, Mizusawa J, Katayama H, Ueno M, Ikeda M, Ozaka M, Okano N, Sugimori K, Fukutomi A, et al. Combination gemcitabine plus S-1 versus gemcitabine plus cisplatin for advanced/recurrent biliary tract cancer: the FUGA-BT (JCOG1113) randomized phase III clinical trial. Ann Oncol. 2019:30(12):1950-8

19. Tsimberidou AM. Targeted therapy in cancer. Cancer Chemother Pharmacol. 2015:76(6):1113-32

20. Kaavya J, Mahalaxmi I, Devi SM, Santhy KS, Balachandar V. Targeting phosphoinositide-3-kinase pathway in biliary tract cancers: a remedial route? J Cell Physiol. 2019;234(6):8259-73.

21. Mahipal A, Tella SH, Kommalapati A, Anaya D, Kim R. FGFR2 genomic aberrations: Achilles heel in the management of advanced cholangiocarcinoma. Cancer Treat Rev. 2019:78:1-7.

22. Mehrotra R, Tulsyan S, Hussain S, Mittal B, Singh Saluja S, Singh S, Tanwar P, Khan A, Javle M, Hassan MM, et al. Genetic landscape of gallbladder cancer: global overview. Mutat Res. 2018;778:61-71.

23. Mishra SK, Kumari N, Krishnani N. Molecular pathogenesis of gallbladder cancer: An update. Mutat Res. 2019;816-818:111674. 
24. Peng H, Zhang Q, Li J, Zhang N, Hua Y, Xu L, Deng Y, Lai J, Peng Z, Peng B, et al. Apatinib inhibits VEGF signaling and promotes apoptosis in intrahepatic cholangiocarcinoma. Oncotarget. 2016;7(13):17220-9.

25. Wang LY, Gong S, Gao LP, Hou LX, He W. Apatinib for treating advanced intrahepatic cholangiocarcinoma after failed chemotherapy: a case report and literature review. Medicine (Baltimore). 2018:97(49):e13372.

26. Zheng Y, Tu X, Zhao P, Jiang W, Liu L, Tong Z, Zhang H, Yan C, Fang W, Wang $W$. A randomised phase II study of second-line XELIRI regimen versus irinotecan monotherapy in advanced biliary tract cancer patients progressed on gemcitabine and cisplatin. Br J Cancer. 2018;119(3):291-5.

27. Blair AB, Murphy A. Immunotherapy as a treatment for biliary tract cancers: a review of approaches with an eye to the future. Curr Probl Cancer. 2018; 42(1):49-58.

\section{Publisher's Note}

Springer Nature remains neutral with regard to jurisdictional claims in published maps and institutional affiliations.

Ready to submit your research? Choose BMC and benefit from:

- fast, convenient online submission

- thorough peer review by experienced researchers in your field

- rapid publication on acceptance

- support for research data, including large and complex data types

- gold Open Access which fosters wider collaboration and increased citations

- maximum visibility for your research: over $100 \mathrm{M}$ website views per year

At BMC, research is always in progress.

Learn more biomedcentral.com/submissions 